\title{
ANALYSIS OF UTILIZATION BATTERY ENERGY STORAGE SYSTEMS FOR FREQUENCY REGULATION
}

\author{
Tomáš KOŠICKÝ, Lubomír BEŇA, Michal KOLCUN \\ Department of Electrical Power Engineering, Faculty of Electrical Engineering and Informatics, \\ Technical University of Košice, Masiarska 74, 04120 Kosice, tel. +421 55602 3560, \\ e-mail: tomas.kosicky@tuke.sk, lubomir.bena@tuke.sk,kolcun.michal@gmail.com
}

\begin{abstract}
The possibility of dynamic energy storage such as auxiliary function FACTS regulator offers to control flows of active and reactive power in an attachment point to the system. Dynamic control of active and reactive power is running independently from each other. Reactive regulation power provides voltage control and network stability with a huge dynamic response. Integration possibilities of energy storage in a chemical form into the storages, has a potential to bring significant advantages for the transmission operators and distributional networks. Increasing distributed share production, which is based in part on the renewable energy sources, leads to the storage need for some needs that offer ancillary services and allow reliable, cost-effective and quality electricity supply. In this paper, we present a method which allows to keep the optimal amount of SoC. deal with SoC level balancing (to 50\%) by identifying Active Frame (AF), Frame of Charge (FoC), Frame of Discharge (FoD), SoC deflection predictions and its balancing with as little DoD cycle change as possible.
\end{abstract}

Keywords: BESS, EoL, SoC, DoD, VSC, FoC, FoD

\section{INTRODUCTION}

Power reserve sequence is intended for the situation, when we have to deal with sudden, unexpected shortfalls in the production or in the electricity transmission and also with a sharply increasing load. Primary, secondary and tertiary regulation reserve is gradually available in time reserve disposition. Primary regulation of active power maintains a balance between the production and electricity consumption within synchronous area, which is using the speed regulation or active power device that provides the ancillary services. The activity aim of all interconnected power systems is operational safety energy system in a synchronous area and it is stabilizing system frequency to the equilibrium value after some damage within the time of frame seconds, but without the recovery set point frequency system and the scheduled exchanges of active power. For the year 2013 the contribution of Slovakia was under the common transmission network ENTSO-E $\pm 29 \mathrm{MW}[1]$. Accumulating battery systems should absorb or supply the energy according to the same demands like a present providers PRV (Primary regulative power) in a real time without delaying, which is typical for rotating machines. The frequency range of the primary regulation active power will be $\Delta f= \pm 200 \mathrm{mHz}$ and the non - sensitivity zone of the regulator and active power device, which provides primary regulation stays at the value of $\eta< \pm 10 \mathrm{mHz}$. To compare the lifetime changes, we will evaluate the primary regulation model of the non - sensitivity zone $\eta< \pm 20 \mathrm{mHz}$ [2].

Battery energy storage systems (BESS) that are connected on the secondary side through the transformer phase to the distribution network represents an alternative to traditional maintenance strategy of an adequate margin - call backup for the reduction of frequency fluctuations. In response to frequency deviations, the systems for the energy accumulating can deliver primary regulation power (primary reserve). It means that fixed energy which is placed into the several cycles for some time allows to the transmission network operators to decreasing or removing the purchase need and ancillary services of primary regulation which is provided by conventional providers.

The FACTS systems with an accumulation combine the storage of energy in high-voltage lithium-ion battery with static reactive power compensator for the compensation and for the reactive power and the dynamic voltage control. The technology which is called Voltage Source Converter (VSC) has an advantage, because it is able to change operating point. It means that it can work in four quadrants and manage independently active and reactive power. STATCOM with an energy accumulation, it is able to regulate reactive power like an ordinary SVC, and also an active power thanks to batteries which can be used like a support of dynamic stability and distribution network by the most effective combination of active and reactive power [3].

\section{STORAGE SYSTEM FOR FREQUENCY CONTROL}

As we have already known, STATCOM is a static synchronous compensator that is used like a reactive power regulator. With STATCOM the absorbed reactive power can be changed, while in contrast to the SVC systems, it does not contain any mechanical switching elements and it is able to cope with a much faster changes, for example voltage or fast change of reactive power flow.

The energy accumulation, which can be a STATCOM part, is based on the battery chain. The huge energy amount is needed and the demanded time of discharging and charging is in a range from several minutes to several hours $[4,5]$, the batteries are connected into series for getting demanding voltage and then parallel demanded power. The picture no.1 illustrates STATCOM systems with BESS, which consists of VSC and with serially 
connected battery rows on one side for achieving higher power. Every battery series consist of series - connected batteries to achieve the desired voltage level.

If the minimum requirements do we consider arranging the batteries and making them able to supply/demand $\pm 2 \mathrm{MW}$, the active power during 15 minutes, then the minimum energy capacity of the batteries is $2 \mathrm{MWh}$. The charging level system $(\mathrm{SoC})$ is maintained at the level about $50 \%$ of the whole capacity. The energy accumulation is designed for the energy capacity $2 \mathrm{MWh}$ to ensure sufficient margin for PRV and also to cover the capacity losses. Table 1. describe activated regulation power of BESS depends on frequency deviation.

The battery cell has a discharging power $146 \mathrm{~W}$ to the one cell. For the energy capacity $2 \mathrm{MWh}$ there is needed the minimum battery cells at the number 13698 [7]. Parallel battery chains provide one way nominal converter voltage and the flow, which is needed in a discharging time. 13698 installed articles are then divided into two orders. In the consideration formats, there is installed battery capacity system 2 MWh.

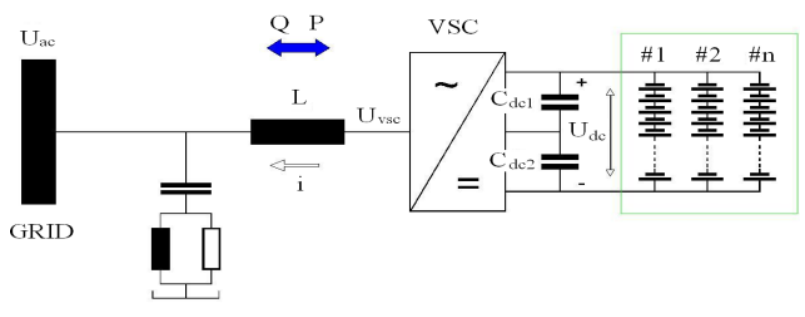

Fig. 1 Schematic layout of STATCOM with Energy Storage

If we are aware with the PRV granting condition, the maximal power must be able at least for 15 minutes, after those it will be activated secondary frequency regulation. In transmission network terms, the storage system can with the reduced accumulation demand some acts that can be repeated pretty often, because the interventions for changing power levels avoid imposing too much power on one side or another side. The methodology which was chosen to maintain the batteries within the limits $\mathrm{SoC}$ is counting with $50 \%$ reserve, that covers losses of the battery capacity and with and regulative algorithm, in which each successive 15 minute interval balances $S o C$ at the level of $50 \%$.

In battery terms, it has a restriction on the degree SoC charge two main consequence. At first, every charging and discharging cycle will represent bigger percentage share of installed energy, which means that the cycle can be used even faster. The second thing is that the fluctuations in the ratio of the depth and discharge $(D o D)$ during charging and discharging can be too high to be compatible with long-term battery life. For ordinary Li ion batteries with a graphite negative electrodes, the charging and discharging at high values $D o D$ can lead to significantly premature aging, which is caused by the lithium plating processes [8]. The acceptable power during the charging and discharging is the battery type function. The next factor is that the BESS systems can be lighter in balanced position if they can provide multiple values energy at the slightest fluctuations into positive or negative $D o D$.

\section{POWER-FREQUENCY RESPONSE OF THE STORAGE SYSTEM}

The picture no. 2 illustrates the frequency process (left) in a time and the characteristics of primary frequency regulation (right). In a time, when the frequency is in a non - sensibility process, at the upper border, the battery is charging. If the frequency is under the lower limit in a non - stability process, the battery is discharging.

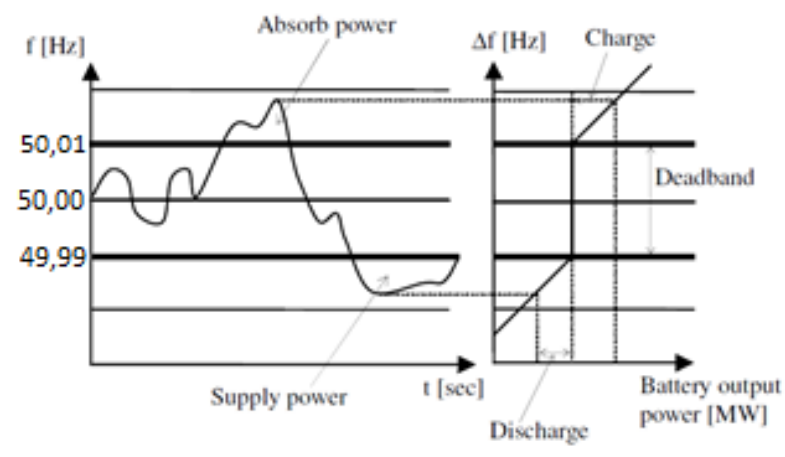

Fig. 2 Operation principle

While the frequency deviation at nominal frequency 50 $\mathrm{Hz}$ can be positive or negative, the battery accumulation SoC should by in a position when it allows discharging at any time $\left(f_{(t)}<49,99 \mathrm{~Hz}\right)$, and also charging $\left(f_{(t)}>50,01 \mathrm{~Hz}\right)$. For this reason the normal battery charging level $S o C$ is $50 \%$. It is because after the discharging cycle, there may appear another discharging cycles and the battery accumulation can finish as absolutely discharged. The $S o C$ level will achieve the border of $S o C$ min. Similarly there can appear some several consecutive cycles and the battery accumulation will achieve the level of $S o C$ max.

It should be noted that the operations in picture no. 3 is due to the fact that the frequency has not gone the whole time through the non - sensitivity zone. These operations in the non - sensibility zone represent $\eta< \pm 10 \mathrm{mHz}$ $57,44 \%$ the total amount of cycles, in non -sensibility zone $\eta< \pm 20 \mathrm{mHz} 77,28 \%$ the total amount of cycles. The operations in the non - sensibility zone are not counted into the capacity losses. To keep the battery in the middle of $S o C$ zone, it demands the independent power for charging or discharging, when the frequency in non sensibility zone or when the $\mathrm{SoC}$ level is out of tolerance level, which is at this case estimated value from $45 \%$ to $55 \%$.As we can see in the picture no. 4 , in the analysed week there was BESS in most cases in the range, where the $S o C$ value exceeded the $55 \%$ value, which is causes by the frequency deviations occur predominantly in $f_{(t)}>50,00 \mathrm{~Hz}$.

If the frequency is in non - sensibility zone, the battery power has a value that corresponds with the battery level, which is in our model maintained at $\mathrm{SoC}$ level of $45-55 \%$.

Regulation power supplied $f(t)<49,99 \mathrm{~Hz}$ : 


$$
P_{\mathrm{dod}}=\int_{t=1}^{900} P_{\mathrm{dod}}(t) d t
$$

Consumed regulation power $f(t)>50,01 \mathrm{~Hz}$ :

$$
P_{\mathrm{odob}}=\int_{t=1}^{900} P_{\mathrm{odob}}(t) d t
$$

Similarly, when the frequency is in non - sensibility zone and if the battery charging level is under the minimal value, which is in this case $45 \%$, the battery is charging according to $\mathrm{SoC}$ so that in the next 15 minute interval will be able to achieve the balance. The plane of the zero power in the sketch is continuously rising and decreasing and creating a black area in the picture no. 3 .

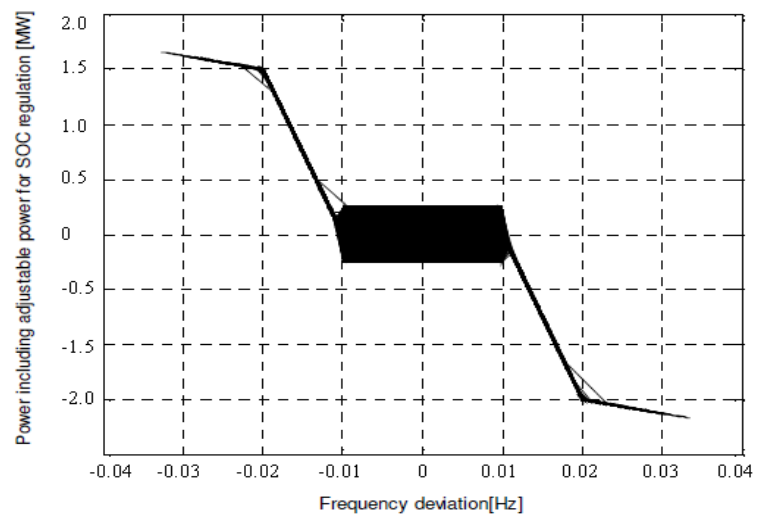

Fig. 3 Power-frequency characteristic having

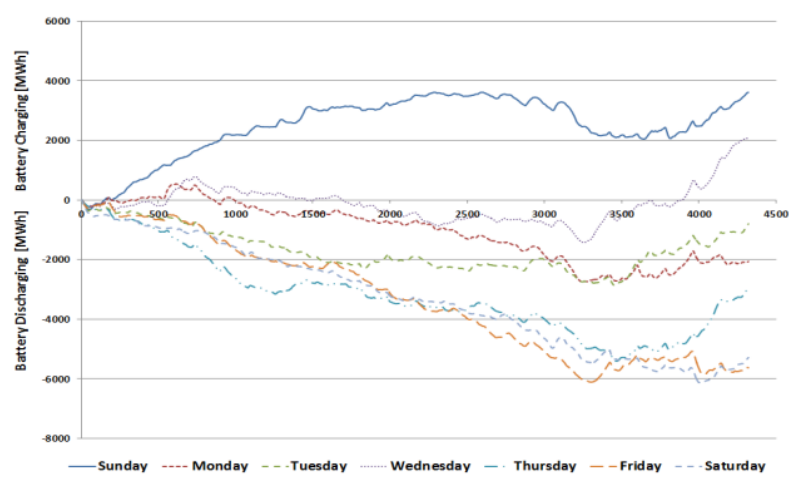

Fig. 4 SOC level as a function of time for week

The $S o C$ levels in the picture no. 4 in the analysed week lied between $5 \%$ and $99 \%$ of the battery capacity value, thus the deployability condition is made for the supply of primary control power. The battery accumulation $\pm 2 \mathrm{MWh}$ is fine for the frequency regulation in simulation area.

SoC calculation:

$S o C_{\mathrm{avg}}=\frac{1}{\Delta \mathrm{t}} \int_{t_{n-1}}^{t_{n}} \operatorname{SoC}(t) d t$

\section{ESTABLISHMENT OF A CONTROL CIRCUIT SOC}

Picture no.5 illustrates the imposing regulation $S o C$, where the $f$ is a network frequency and $P$ is the power according to the characteristics. 1 and $S o C$ is the charging level.

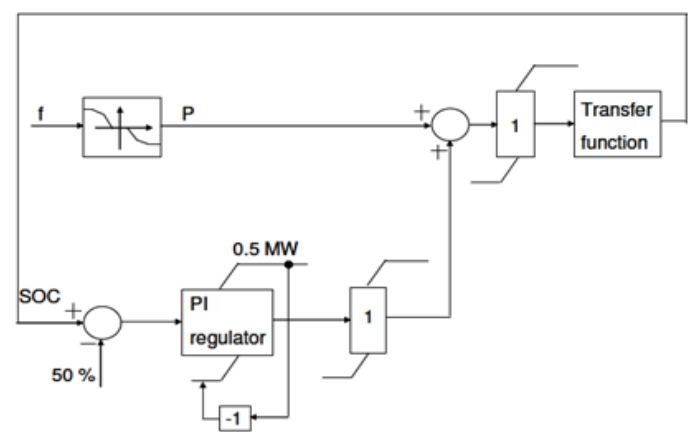

Fig. 5 SoC level as a function of time for week, having a SoC control loop

To evaluate bigger SoC powers, it is necessary not to notice minor capacity fluctuations in the non - sensibility zone. The filtration level of course, will influence the results. The inclusion of the filtration level in non sensibility zone covers the losses that are connected with keeping the system at $50 \%$. In order to keep the level of the $S o C$ operating point, the whole power $P_{\text {ext }}(t)$ is counted as a sum $P_{\mathrm{AS}}(t)$ (ancillary service) and a operating point BESS signal $P_{\mathrm{WP}}(t)$ (operating point).

$$
P_{\mathrm{ext}}(t)=P_{\mathrm{AS}}(t)+P_{\mathrm{WP}}(t)
$$

The resulting power is counted as a $S o C$ difference between maximum and minimum, which is achieved in a 15 minutes interval, which can be later expressed as a power PAS $(t)$ by the capacity unit [MW/MWh].

\section{THE LIFE CYCLE OF LI-ON BATTERY}

Batteries degrade predictably when they are submitted of controlled repeated charging and discharging cycles. Picture no.6 illustrates the life-cycle curve of Li-ion battery system, based on the $D o D$ depth discharging for every cycle $[6,7]$.

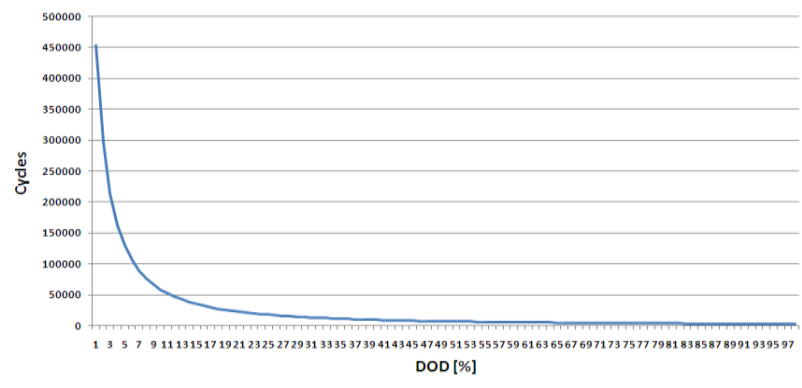

Fig. 6 Cycle-life curve for the lithium-ion battery system 
The capacity loss calculation:

$$
y=2498 \cdot x^{-1483} \quad R^{2}=0,999
$$

$R^{2}$ is the real component of giving depth to the battery discharge $D o D$ and $y$ is the number of cycles pertaining to the value of $D o D$.

The capacity losses sum:

$$
E o L_{\text {TOTAL }}=\sum_{i=1}^{n} E o L(c y c)_{i}
$$

Calculating the level of battery power:

$$
\begin{aligned}
& \Delta E\left(t_{i}\right)=\frac{\left[M W\left(t_{i}\right)+M W\left(t_{i_{-1}}\right)\right] \cdot\left(t_{i}-t_{i-1}\right)}{2} \\
& \operatorname{SOE}\left(t_{i}\right)=\operatorname{SOE}\left(t_{i-1}\right)+\frac{\Delta E\left(t_{i}\right)}{\text { Battery_ratting(MWh) }}
\end{aligned}
$$

Calculation the end of capacity in days:

$$
E o L=\frac{\left(\frac{\Delta E o L}{50}\right)}{T}
$$

\section{ANALYSIS DURING FREQUENCY CONTROL USING BESS}

In the analysed week 37/2012 we applied the calculation for every day separately, and we compared introduction of two non - sensibility zones $\eta< \pm 10 \mathrm{mHz}$; $\eta< \pm 20 \mathrm{mHz}$. Picture no.7 illustrates the hour process of analysed frequency.

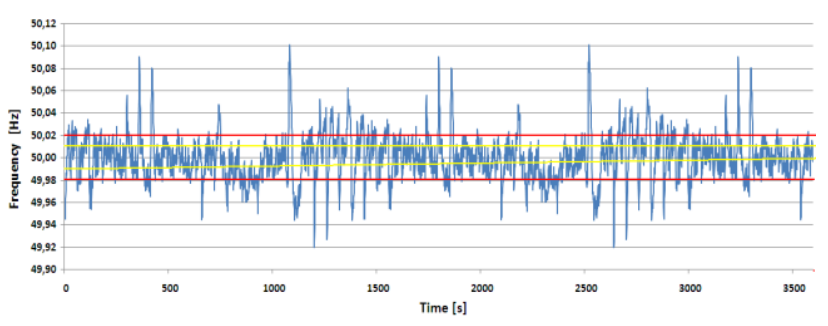

Fig. 7 Hour of analysed frequency

In the picture no. 9 we can see the frequency process, which is divided by algorithm cycles, where the end of the cycle is always bounded by the frequency value change, caused by rising and falling. Picture no. 8 .

$$
\begin{array}{cc}
\mathrm{f}_{(t)}>50,01 \mathrm{~Hz} & \mathrm{f}_{(t)}<\mathrm{f}_{(t+1)} \rightarrow \text { cycle '+' } \\
\mathrm{f}_{(t)}>\mathrm{f}_{(t+1)} \rightarrow \text { cycle '-' } \\
\mathrm{f}_{(t)}<49,99 \mathrm{~Hz} & \mathrm{f}_{(t)}>\mathrm{f}_{(t+1)} \rightarrow \text { cycle }-{ }^{\prime} \\
\mathrm{f}_{(t)}<\mathrm{f}_{(t+1)} \rightarrow \text { cycle '+' }
\end{array}
$$

For better imagination, in the picture no. 9, there is showed only the biggest of 30 cycles in the analysed hour. In one cycle, the difference of deviations system in frequency $\Delta f$ according to Tab. 1 .
Table 1 indicates the value of primary activated

\begin{tabular}{|c|c|c|c|c|c|c|}
\hline $\begin{array}{c}\text { Activation } \\
\text { time } \\
{[0-30 s]}\end{array}$ & $\begin{array}{c}\text { Positive } \\
\text { frequency } \\
\text { difference } \\
{[\mathrm{Hz}]}\end{array}$ & $\begin{array}{c}\text { Negative } \\
\text { frequency } \\
\text { difference } \\
{[\mathrm{Hz}]}\end{array}$ & \begin{tabular}{|c} 
Activated \\
regulation \\
power \\
without BESS \\
{$[\mathrm{MW}]$}
\end{tabular} & $\begin{array}{c}\text { Activated } \\
\text { regulation } \\
\text { power with } \\
\text { BESS } \\
{[\mathrm{MW}]}\end{array}$ & $\begin{array}{c}\text { Percentage } \\
\text { charge / } \\
\text { Regulation } \\
\text { power } \\
{[\% / \mathrm{MW}]}\end{array}$ & $\begin{array}{c}\text { Activated } \\
\text { regulation } \\
\text { power } \\
\text { overall } \\
\text { [MW] }\end{array}$ \\
\hline 1 & 50,00667 & 49,99333 & 0,9 & 0,07 & 3,3333 & 0,97 \\
\hline 2 & 50,01334 & 49,98666 & 1,8 & 0,13 & 6,6633 & 1,93 \\
\hline 3 & 50,02001 & 49,97999 & 2,7 & 0,20 & 9,9933 & 2,90 \\
\hline 4 & 50,02668 & 49,97332 & 3,6 & 0,27 & 13,3233 & 3,87 \\
\hline 5 & 50,03335 & 49,96665 & 4,5 & 0,33 & 16,6533 & 4,83 \\
\hline 6 & 50,04002 & 49,95998 & 5,4 & 0,40 & 19,9833 & 5,80 \\
\hline 7 & 50,04669 & 49,95331 & 6,3 & 0,47 & 23,3133 & 6,77 \\
\hline 8 & 50,05336 & 49,94664 & 7,2 & 0,53 & 26,6433 & 7,73 \\
\hline 9 & 50,06003 & 49,93997 & 8,1 & 0,60 & 29,9733 & 8,70 \\
\hline 10 & 50,0667 & 49,9333 & 9 & 0,67 & 33,3033 & 9,67 \\
\hline 11 & 50,07337 & 49,92663 & 9,9 & 0,73 & 36,6333 & 10,63 \\
\hline 12 & 50,08004 & 49,91996 & 10,8 & 0,80 & 39,9633 & 11,60 \\
\hline 13 & 50,08671 & 49,91329 & 11,7 & 0,87 & \begin{tabular}{|l|}
43,2933 \\
\end{tabular} & 12,57 \\
\hline 14 & 50,09338 & 49,90662 & 12,6 & 0,93 & 46,6233 & 13,53 \\
\hline 15 & 50,10005 & 49,89995 & 13,5 & 1,00 & 49,9533 & 14,50 \\
\hline \begin{tabular}{l|l|}
16 & \\
\end{tabular} & 50,10672 & 49,89328 & 14,4 & 1,07 & 53,2833 & 15,47 \\
\hline 17 & 50,11339 & 49,88661 & 15,3 & 1,13 & 56,6133 & 16,43 \\
\hline 18 & 50,12006 & 49,87994 & 16,2 & 1,20 & 59,9433 & 17,40 \\
\hline 19 & 50,12673 & 49,87327 & 17,1 & 1,27 & 63,2733 & 18,37 \\
\hline 20 & 50,1334 & 49,8666 & 18 & 1,33 & 66,6033 & 19,33 \\
\hline 21 & 50,14007 & 49,85993 & 18,9 & 1,40 & 69,9333 & 20,30 \\
\hline 22 & 50,14674 & 49,85326 & 19,8 & 1,47 & 73,2633 & 21,27 \\
\hline 23 & 50,15341 & 49,84659 & 20,7 & 1,53 & 76,5933 & 22,23 \\
\hline 24 & 50,16008 & 49,83992 & 21,6 & 1,60 & 79,9233 & 23,20 \\
\hline 25 & 50,16675 & 49,83325 & 22,5 & 1,67 & 83,2533 & 24,17 \\
\hline 26 & 50,17342 & 49,82658 & 23,4 & 1,73 & 86,5833 & 25,13 \\
\hline \begin{tabular}{l|l|}
27 \\
\end{tabular} & 50,18009 & 49,81991 & 24,3 & 1,80 & 89,9133 & 26,10 \\
\hline 28 & 50,18676 & 49,81324 & 25,2 & 1,87 & 93,2433 & 27,07 \\
\hline 29 & 50,19343 & 49,80657 & 26,1 & 1,93 & 96,5733 & 28,03 \\
\hline 30 & 50,2001 & 49,7999 & 27 & 2,00 & 99,9033 & 29,00 \\
\hline
\end{tabular}
regulation power.

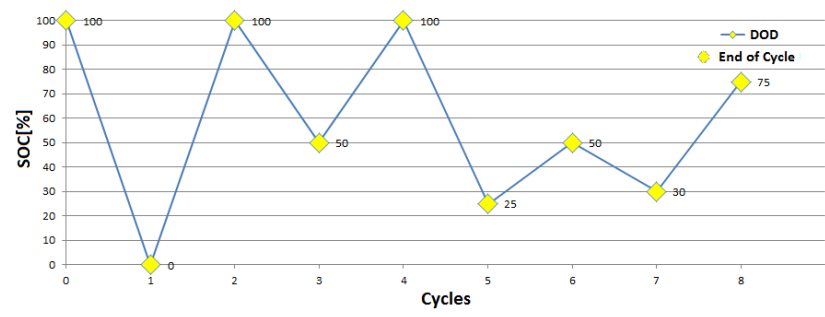

Fig. 8 Identified of cycles according $S o C$ level

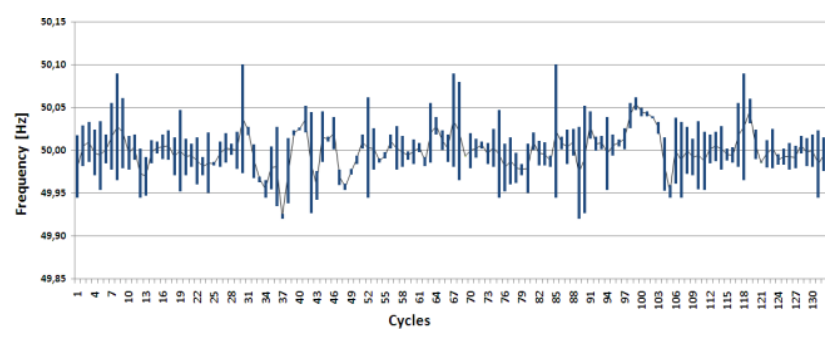

Fig. 9 During the division of frequencies to cycles

Table 1 Dependence of regulation power from the system frequency deviation

Estimated battery life on basis of identifying the sub cycles then comes from the chart during the battery life. In the picture no. 6 , where is for every cycle, which is based on the $D o D$ assigned the capacity loss. The individual losses sum creates the total capacity loss of BESS. It is important to realize that this value is constantly decreasing and it decreases the total available power system. If we 
consider, that in $50 \%$ of the capacity loss we will have to replace individual battery cells or decrease minimum possible PRV, we must take into account this parameter also in determining the economic benefits by BESS.

Table 2 Identified sub cycles $\eta< \pm 10 \mathrm{mHz}$

\begin{tabular}{|c|c|c|c|}
\hline $\begin{array}{c}\text { Center } \\
\text { SOC }\end{array}$ & $\begin{array}{c}\text { SOC } \\
\text { Swing }\end{array}$ & $\begin{array}{c}\text { Micro Cycles } \\
\text { per day }\end{array}$ & $\begin{array}{c}\text { Capacity loss } \\
{[\%]}\end{array}$ \\
\hline 0,01 & $<2 \%$ & 2657 & 0,003215338 \\
\hline 0,03 & $2^{\sim} 4 \%$ & 1145 & 0,00252804 \\
\hline 0,05 & $4^{\sim} 6 \%$ & 0 & 0 \\
\hline 0,07 & $6^{\sim} 8 \%$ & 621 & 0,003832635 \\
\hline 0,09 & $8^{\sim} 10 \%$ & 151 & 0,001700302 \\
\hline 0,125 & $10^{\sim} 15 \%$ & 35 & 0,000679913 \\
\hline 0,175 & $15^{\sim} 20 \%$ & 12 & 0,000332519 \\
\hline 0,25 & $20^{\sim} 30 \%$ & 4 & 0,000199152 \\
\hline 0,35 & $30^{\sim} 40 \%$ & 0 & 0 \\
\hline 0,45 & $40^{\sim} 50 \%$ & 0 & 0 \\
\hline 0,55 & $50^{\sim} 60 \%$ & 0 & 0 \\
\hline 0,65 & $60^{\sim} 70 \%$ & 0 & 0 \\
\hline 0,75 & $70^{\sim} 80 \%$ & 0 & 0 \\
\hline 0,85 & $80^{\sim} 90 \%$ & 0 & 0 \\
\hline 0,95 & $90^{\sim} 100 \%$ & 0 & 0 \\
\hline \multicolumn{5}{|l|}{} \\
\hline Total capacity lost per day [\%] & 0,012487899 \\
\hline Total capacity lost per year [\%] & 4,558083193 \\
\hline Years to -50\% capacity (yrs) & 10,96952335 \\
\hline
\end{tabular}

Table 3 Identified sub cycles for $\eta< \pm 20 \mathrm{mHz}$

\begin{tabular}{|c|c|c|c|}
\hline $\begin{array}{c}\text { Center } \\
\text { SOC }\end{array}$ & $\begin{array}{c}\text { SOC } \\
\text { Swing }\end{array}$ & $\begin{array}{c}\text { Micro Cycles } \\
\text { per day }\end{array}$ & $\begin{array}{c}\text { Capacity loss } \\
{[\%]}\end{array}$ \\
\hline 0,01 & $<2 \%$ & 3573 & 0,004323825 \\
\hline 0,03 & $2^{\sim} 4 \%$ & 712 & 0,001572021 \\
\hline 0,05 & $4^{\sim} 6 \%$ & 0 & 0 \\
\hline 0,07 & $6^{\sim} 8 \%$ & 261 & 0,001610818 \\
\hline 0,09 & $8^{\sim} 10 \%$ & 58 & 0,000653096 \\
\hline 0,125 & $10^{\sim} 15 \%$ & 15 & 0,000291391 \\
\hline 0,175 & $15^{\sim} 20 \%$ & 4 & 0,00012107 \\
\hline 0,25 & $20^{\sim} 30 \%$ & 2 & $9,05482 \mathrm{E}-05$ \\
\hline 0,35 & $30^{\sim} 40 \%$ & 0 & 0 \\
\hline 0,45 & $40^{\sim} 50 \%$ & 0 & 0 \\
\hline 0,55 & $50^{\sim} 60 \%$ & 0 & 0 \\
\hline 0,65 & $60^{\sim} 70 \%$ & 0 & 0 \\
\hline 0,75 & $70^{\sim} 80 \%$ & 0 & 0 \\
\hline 0,85 & $80^{\sim} 90 \%$ & 0 & 0 \\
\hline 0,95 & $90^{\sim} 100 \%$ & 0 & 0 \\
\hline \multicolumn{5}{|c|}{} \\
\hline Total capacity lost per day [\%] & 0,008662769 \\
\hline Total capacity lost per year [\%] & 3,161910616 \\
\hline Years to -50\% capacity (yrs) & 15,81322374 \\
\hline
\end{tabular}

The Tables 2. and 3. Illustrates the division of cycles according to the $\mathrm{SoC}$ displacements for analysed day 9.9.2012, where the difference between the non sensibility zones will cause displacement cycle towards lower deflections $\mathrm{SoC}$ and thus to a minor capacity loss.

Picture 10. shows us how to keep the system capacity at equilibrium state, we inducted a regulatory circuit using the fact that after 15 minutes of supplying PRV, secondary frequency regulation will be activated and capacity deflection from $50 \%$ SoC will be regulated in the next 15 minutes.

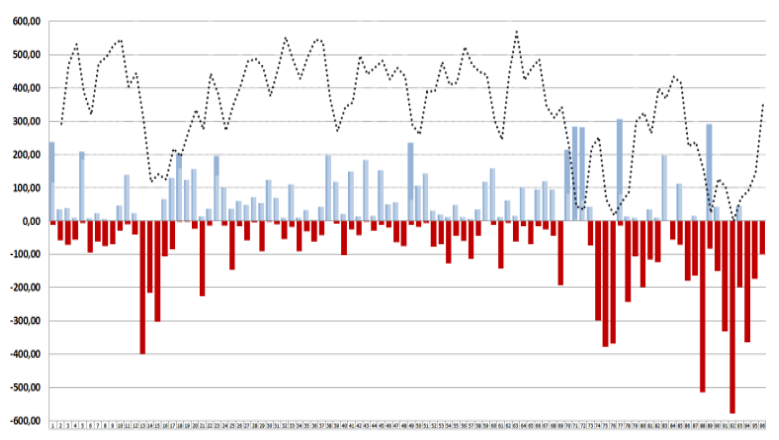

[I Pdod[MW/MWh] = Podob[MW/MWh] **Active framework

Fig. 10 15-minute levels of supplied/taken off power and Active framework

As batteries supply regulation power only when the frequency overpasses the dead zone level $\eta< \pm 10 \mathrm{mHz}$, the power needed to balance the capacity will only be active outside of this interval. $A F$ (Active Framework) is the time during which the system supplies/takes off power.

For every following 15-minute intervals we will supply $F o C$ (Frame of Charge) or take off $F o D$ (Frame of Discharge) power unit to balance $S o C 50 \%$ following this formula:

$$
\begin{aligned}
& F o C= \frac{\sum_{t=1}^{900} P_{\text {TARGET (odob)t }}}{A F} \\
& F o D=\frac{\sum_{t=1}^{900} P_{\text {TARGET (dod) } t}}{A F}
\end{aligned}
$$

After the capacity change, in the first 15 minutes we will balance $S o C 50 \%$ following the formula $P_{\text {ext }}(t)=P_{\mathrm{AS}}(t)$ $\pm P_{\text {soc }}(t)$ where in the next 15 minutes of regulation we will supply/take off $F o C / F o D$ unit in every $A F$ to the required regulation power; we use the presumption that:

$$
\sum_{t=901}^{1800} A F_{t}>\sum_{t=1}^{900} A F_{t}
$$

As Table 4. shows us if the total $A F$ in the time $t=(901,1800)$ is lower than the one in the previous interval, the total needed power to balance $\operatorname{SoC} 50 \%$ was not supplied. The difference between the real $P_{\text {REAL }}(\mathrm{MWh})$ and required power $P_{\text {TARGET }}(\mathrm{MWh})$ is then recalculated to the required supplied/taken off power in the next 15-minute interval following the formula:

$$
\begin{aligned}
& \sum_{\mathrm{t}=901}^{1800} \mathrm{P}_{t}=\left[\sum_{\mathrm{t}=901}^{1800} \mathrm{P}_{\operatorname{TARGET}(D O D) t}-\sum_{\mathrm{t}=901}^{1800} \mathrm{P}_{\operatorname{TARGET}(O D O B) t}\right]+ \\
& +\left[\sum_{\mathrm{t}=901}^{1800} \mathrm{P}_{\mathrm{AB}(O D O B) t}+\sum_{\mathrm{t}=901}^{1800} P_{A B(D O D) t}\right]
\end{aligned}
$$


Table 4 15-minute levels of fluctuations and $\mathrm{SoC}$ balancing

\begin{tabular}{|c|c|}
\hline t900[s] & $\begin{array}{c}\text { Pdod } \\
\text { [MW/MWh] }\end{array}$ \\
\hline 1 & 238,728 \\
\hline 2 & 35,782 \\
\hline 3 & 39,125 \\
\hline 4 & 11,032 \\
\hline 5 & 208,608 \\
\hline 6 & $\begin{array}{l}7,837 \\
\end{array}$ \\
\hline 7 & 23,923 \\
\hline 8 & 6,834 \\
\hline 9 & 1,303 \\
\hline 10 & 46,875 \\
\hline 11 & 139,667 \\
\hline 12 & 23,119 \\
\hline 13 & 0,000 \\
\hline 14 & 0,000 \\
\hline 15 & 0,000 \\
\hline 16 & 65,911 \\
\hline \begin{tabular}{l|l}
17 \\
\end{tabular} & 130,516 \\
\hline 18 & 202,416 \\
\hline 19 & 124,068 \\
\hline 20 & 157,682 \\
\hline 21 & 13,627 \\
\hline 22 & 37,063 \\
\hline 23 & 195,908 \\
\hline 24 & 100,528 \\
\hline 25 & 38,458 \\
\hline 26 & 60,111 \\
\hline 27 & 49,398 \\
\hline 28 & 73,034 \\
\hline 29 & 54,066 \\
\hline 30 & 125,113 \\
\hline 31 & \begin{tabular}{|l|}
70,976 \\
\end{tabular} \\
\hline 32 & 9,737 \\
\hline 33 & 110,275 \\
\hline 34 & 11,210 \\
\hline 35 & 33,745 \\
\hline 36 & 4,060 \\
\hline \begin{tabular}{l|l}
37 \\
\end{tabular} & \begin{tabular}{|l|l|}
43,156 \\
\end{tabular} \\
\hline 38 & 196,842 \\
\hline 39 & 117,490 \\
\hline 40 & 21,744 \\
\hline 41 & 150,110 \\
\hline 42 & \begin{tabular}{|l|}
15,067 \\
\end{tabular} \\
\hline $\begin{array}{ll}43 \\
\end{array}$ & 183,097 \\
\hline 44 & 15,410 \\
\hline \begin{tabular}{l|l}
45 \\
\end{tabular} & 153,401 \\
\hline 46 & 51,476 \\
\hline \begin{tabular}{l|l|}
47 \\
\end{tabular} & 56,653 \\
\hline 48 & 0,000 \\
\hline 49 & 236,796 \\
\hline 50 & 105,927 \\
\hline \begin{tabular}{l|}
51 \\
\end{tabular} & 142,786 \\
\hline 52 & 31,563 \\
\hline 53 & 20,074 \\
\hline 54 & 11,780 \\
\hline 55 & 49,032 \\
\hline \begin{tabular}{l|l}
56 \\
\end{tabular} & 13,232 \\
\hline \begin{tabular}{l|l|}
57 \\
\end{tabular} & 6,184 \\
\hline 58 & 34,997 \\
\hline 59 & 118,540 \\
\hline 60 & 158,140 \\
\hline 61 & 12,352 \\
\hline \begin{tabular}{l|l}
62 \\
\end{tabular} & \begin{tabular}{|c|}
62,266 \\
\end{tabular} \\
\hline 63 & 10,023 \\
\hline $\begin{array}{ll}64 \\
\end{array}$ & 103,700 \\
\hline 65 & 4,516 \\
\hline 66 & 94,801 \\
\hline 67 & 120,890 \\
\hline 68 & 94,430 \\
\hline 69 & 0,145 \\
\hline \begin{tabular}{ll|}
70 \\
\end{tabular} & 213,816 \\
\hline 71 & 284,932 \\
\hline 72 & 283,082 \\
\hline 73 & 43,575 \\
\hline 74 & 0,000 \\
\hline 75 & 0,000 \\
\hline 76 & 0,000 \\
\hline 77 & 307,697 \\
\hline 78 & 13,474 \\
\hline 79 & 10,097 \\
\hline 80 & 0,000 \\
\hline 81 & 34,714 \\
\hline 82 & 10,455 \\
\hline \begin{tabular}{l|l}
83 \\
\end{tabular} & 197,578 \\
\hline 84 & 0,000 \\
\hline 85 & 113,161 \\
\hline 86 & 0,000 \\
\hline \begin{tabular}{l|l|}
87 \\
\end{tabular} & 16,222 \\
\hline 88 & 0,000 \\
\hline \begin{tabular}{l|l|}
89 \\
\end{tabular} & 291,561 \\
\hline 90 & 44,074 \\
\hline 91 & 0,000 \\
\hline 92 & 0,000 \\
\hline 93 & \begin{tabular}{|l|l|}
46,469 \\
\end{tabular} \\
\hline 94 & 0,000 \\
\hline 95 & 0,000 \\
\hline 96 & 1,303 \\
\hline
\end{tabular}

\section{RESULTS}

From this analysis, we can see that the energy storage in battery systems is an effective way how to provide primary control power. Introduction in non - sensibility frequency zone and $\mathrm{SoC}$ regular circuit stores, the batteries within a reasonable range of charging level and minimalizes the impact on battery life. The estimated loss of battery life in $50 \%$ capacity is during increasing in non - sensibility zone from $\eta< \pm 10 \mathrm{mHz}$ to $\eta< \pm 20 \mathrm{mHz}$ it increased from 10,9 the year to 15,8 of the year. The number of the cycles in non - sensibility zone from $57,44 \%$ to $77,28 \%$ by $\eta< \pm 20 \mathrm{mHz}$. It is necessary to establish algorithms in order to keep the system stability so that the capacity losses are as low as possible. At the same time, it is essential not to forget about the losses caused by self-discharging of the batteries (these are the consequence of efficiency of particular charging/discharging cycles). BESS will undoubtedly become popular thanks to the future reduction in costs resulting from expanding employment and mass production of components such as batteries and power elements. In our next paper, we tend to evaluate the algorithms of accumulation equilibrium state balancing in detail; consequently, in case of capacity loss and further support needed, such as voltage stability and accumulation of renewable sources energy.

\section{CONCLUSIONS}

In our analysis we did not put the attention on economic benefits quantification of BESS devices, but with predicted prices decreasing for the installed capacity unit of electricity and density increasing of electricity, which is stored in the battery system, in next the years we expect wider BESS deployment systems in distributional networks.

\section{ACKNOWLEDGMENTS}

This work was supported by Scientific grant agency of the Ministry of Education of the Slovak Republic and of Slovak Academy of Sciences, project VEGA 1/0388/13.

\section{REFERENCES}

[1] Technické Podmienky Prístupu a Pripojenia, Pravidlá Prevádzkovania Prenosovej Sústavy, SEPS 2012.

[2] B. J. KIRBY, " Frequency Regulation Basics and Trends," DOE report TM-2004/291, 2004.

[3] EPRI-DOE Handbook, "Energy Storage for Transmission and Distribution Applications", Dec 2003.

[4] A. NOURAI. (2003, Dec.). Comparison of the Costs of Energy StorageTechnologies for T\&D Applications,[Online].

Available:http://electricitystorage.org/pubs/2004/EP RIDOE\%20Storage\%20Costs-ESA.pdf 
[5] J. SVENSSON - W. HERMANSSON, "Dynamic Energy Storage using SVC Light," Cigré conference Paris, France, August 24-19, 2008.

[6] Proceedings of Electrical Energy Storage Applications and Technologies (EESAT) Oct 2009, Seattle.

[7] IEEE Draft Recommended Practice for the Characterization and Evaluation of Emerging Energy Storage Technologies in Stationary Applications, IEEE Standard P1679TM/D13-2010, Jan. 2010.

[8] Power and Energy Capacity Requirements of Storages Providing Frequency Control Reserves, IEEE 2013.

Received June 11, 2014, accepted October 11, 2014

\section{BIOGRAPHIES}

Tomáš Košický was born on 05.04.1983. In 2008 he graduated (Ing.) with distinction at the Department of Electric power engineering of the Faculty of Electrical Engineering and Informatics at Technical University in Košice. He defended his Ing. degree with the masters diploma thessis "Contribution to network stability". Since 2010 he is external PhD student on Department of electrical power engineering. His scientific research is focusing on Application of the FACTS devices in electric power system control.

Lubomír Beňa was born in 1975 in Bardejov, Slovakia. In 1998 he graduated (MSc.) at the Department of Electrical Power Engineering, Faculty of Electrical Engineering and Informatics, Technical University of Košice. He defended his $\mathrm{PhD}$. in the field of overhead power lines mechanics in 2001. Since 2010 he is associated professor at the Department of Electrical Power Engineering. His scientific research is analysis of electrical power systems and optimization problems in electrical power engineering.

Michal Kolcun was born on 03.10.1979. In 2004 he graduated (Ing.) with distinction at the Department of Electric power engineering of the Faculty of Electrical Engineering and Informatics at Technical University in Košice. Since 2004 until 2007 he was working for company SAT, Systémy automatizačnej techniky, s.r.o. In years 2008 until 2013 he was working for company Energo Consulting, s.r.o. In both companies he designed, configured and commissioned control and SCADA systems for different thermal, nuclear and hydro power plants and substations. Since year 2014 he has been working as project manager in company SAT, Systémy automatizačnej techniky, s.r.o. 